high levels of personal support, which suggests that for those individuals who score worse than the sample as a whole in terms of health or psychological functioning, family support alone may not be sufficient. Also in this 'highest risk' category are the very old ( $15 \%$ of the sample), and the divorced/separated who are mainly to be found in the younger age groups.

Dee Jones, Christina Victor and Norman Vetter, Carers of the elderly in the community. Joumal of the Royal College of General Practitioners, 33 (1983), 707-710.

This study examines the nature of help which the over-7os receive with tasks of everyday living. The sample is drawn from a large urban general practice in South Wales, and 657 patients were interviewed to assess their physical, mental and social well-being, and explore their need for assistance. The most commonly mentioned tasks for which help was needed were the washing and ironing of clothes and travelling by bus. A third of main helpers were themselves over 65 , and one in ten over 75. Daughters were named most frequently as the main helper, followed by spouses, thus confirming the finding of other studies of carers that the family bears the major part of the burden of caring for the elderly. Only a minority of helpers worked for a living, but five (four women, one man) had given up work to look after their relatives.

The home help service was the only significant source of help from the statutory or voluntary service, and almost exclusively was directed to those living alone. The family carers were often unaided, and over time suffered from social isolation, which exacerbated the vulnerability of the elderly should their carer become ill or otherwise unable to cope.

Thus we have yet more evidence of the neglect of family carers by the formal services, and testimony of the continued importance of family support for the vast majority of elderly and disabled people.

\title{
Psychology and Psychiatry
}

\section{Jeffrey Garland}

Larner, Stuart L. . and Leeming, James T. The work of a clinical psychologist in the care of the elderly, Age and Ageing, 13 (1984), 29-33.

Close to tears and very angry, the 86-year-old woman in a geriatric rehabilitation ward told me her grievances. It was almost in passing that 
she mentioned the recent amputation, due to circulatory failure, of her right leg below the knee. Other losses seemed to bother her more. 'I've got no teeth. They took them away to clean them and now they tell me they're lost. And these are my spare glasses - my best pair got dropped here and they're broken.

'What's the time? I don't know - I've got three watches - at home!'

Even her anger seemed mild beside the cold fury of an 84-year-old resident of 'the confused wing' of an old people's home later that day. Twisted like a dry stick, hunchbacked and pigeon-chested, she came out fighting when I asked her how she was.

'Waiting, that's how. Waiting for Christmas, that's what I think. Look at me! I ought to be in Belsen. Look at me.'

Such witnesses, I suggest, not only give vent to their individual distress, but also mirror for us a common dilemma in care of the elderly, in that it is rare to find resolution of physical or psychological needs. Urgent problems are dealt with after a fashion, and the great majority of carers and supporters work with dedicated concern, but disagreement and frustration are all too common, as these authors suggest.

Looking at the day-to-day involvement of Stuart Larner in clinical practice with the elderly in Manchester, this paper singles out seven approaches (which are not mutually exclusive): cognitive assessment; behavioural assessment; advice on handling disruptive 'problem' behaviours; reduction of lethargy and 'confusion'; training in the activities of daily living; reduction of personal distress and behavioural psychotherapy; advice on overall management strategies.

Useful vignettes are given in illustration of the first five of these approaches, in making a case for a clinical psychologist, selectively used, to be a resource of special value 'to knit the rehabilitation team together and to improve its confidence and effectiveness'. For a fuller description of the contribution a clinical psychologist can make to this client group, Woods $\mathbf{s}^{\mathbf{1}}$ is recommended.

Larner and Leeming offer a worthwhile addition to the very limited literature on clinical psychology's service provision for the elderly, which is currently expanding fast while funding lasts. Fresh ways of using practitioner time are being explored. One of my most rewarding recent experiences in Oxford has been as a member of a planning team designing a new old people's home to take account as far as possible of future residents' physical and psychological needs. And in Larner's own service in Manchester an important innovation this year is the establishment of a health education resource centre for the elderly, their carers and supporters.

As more areas of Britain adopt the model of centres such as 
Nottingham or Bristol, in moving towards unified departments of health care for the elderly which cut across traditional boundaries between geriatrics and psychiatry, psychologists can be expected to take on a more positive role in primary care.

However, the excitement of such changes should not seduce us from working to improve the quality of life for old people already in residential care. Many major training packages for health or social services care staff have recently been published or are in preparation, and in general these appear to offer a balanced perspective in confronting the wide range of needs shown by elderly residents.

As Jeffery and Saxby ${ }^{2}$ suggest, the practitioner needs to maintain individual clinical consultancy, but at the same time 'should be aiming to link into a network of professional relationships so that work can be initiated that will have a wider and more lasting impact... service facilitation and evaluation, training, project research and community care aspects' (p. 276).

Realistically, they caution: 'There is a danger that this may be little more than a rather grandiose hope, and in practice we must begin with what is possible.'

Larner and Leeming are currently exploring the art of the possible with due modesty and I commend their paper as a straightforward glimpse of what (when the clouds of professionalising rhetoric are rolled away), clinical psychology actually contributes.

\section{Oxford District Health Authority}

I Woods, R. The psychology of ageing : assessment of defects and their management. In Levy, R. and Post, F. (eds), The Psychiatry of Late Life. Blackwell Scientific Publications, Oxford, 1982, pp. 68-1 I3.

2 Jeffery, D. and Saxby P. Effective psychological care for the elderly. In Hanley, I. and Hodge, J. (eds), Psychological Approaches to the Care of the Elderly. Croom Helm, London, 1984, pp. 255-282. 